\title{
Letter to the Editor Regarding "Impact of Chloroprocaine on the Eligibility for Hospital Discharge in Patients Requiring Ambulatory Surgery Under Spinal Anesthesia: An Observational Multicenter Prospective Study"
}

Elsbeth J. Wesselink (D) - Marcel A. de Leeuw

Received: April 22, 2020 / Published online: June 20, 2020 (c) The Author(s) 2020

Keywords: Ambulant; Anesthesia; Chloroprocaine; Dose; Spinal

We read with considerable interest the article by Capdevila and colleagues concerning the impact of chloroprocaine on the eligibility for hospital discharge in patients requiring ambulatory surgery under spinal anesthesia [1]. We encourage the analysis of spinal chloroprocaine anesthesia as a possible alternative for spinal lidocaine anesthesia and therefore congratulate the authors on this publication. We would like to make a few comments regarding the primary outcomes.

The hospital discharge in this observational multicenter prospective study was $256.6 \pm 80.7 \mathrm{~min}$ (mean $\pm \mathrm{SD}$ )/median 245.0 (range 90-538) min for orthopedic procedures under spinal anesthesia with chloroprocaine. The most common dose of chloroprocaine administered spinally was $50 \mathrm{mg}(59.2 \%)$, then

Digital Features To view digital features for this article go to https://doi.org/10.6084/m9.figshare.12459125.

E. J. Wesselink ( $₫)$

Department of Clinical Pharmacy, Zaans Medisch

Centrum, Zaandam, The Netherlands

e-mail: e.wesselink@amsterdamumc.nl

M. A. de Leeuw

Department of Anesthesiology, Amsterdam UMC,

Amsterdam, The Netherlands
$40 \mathrm{mg}$ (32.3\%). We recently conducted a double-blind randomized trial comparing $40 \mathrm{mg}$ chloroprocaine with $40 \mathrm{mg}$ prilocaine for spinal anesthesia in ambulatory knee arthroscopy [2]. Using exactly the same discharge criteria, we found that the time from injection to eligibility for hospital discharge in the chloroprocaine arm (40 mg) in our study was substantial shorter, i.e., $222 \pm 72$ min (mean $\pm \mathrm{SD}$ ). The use of different dosages of spinal anesthesia using chloroprocaine resulting in different hospital discharge times suggests a possible correlation and therefore we recommend that the authors perform a subgroup analysis (40 mg/50 mg chloroprocaine) to analyze this phenomenon within their cohort.

Furthermore, there was a similarity in effectiveness of spinal anesthesia using $40 \mathrm{mg}$ chloroprocaine in our study compared to $40 \mathrm{mg}$ $(32.3 \%) / 50 \mathrm{mg}(59.2 \%)$ in Capdevila et al.'s cohort. We reported a success rate of spinal anesthesia in the chloroprocaine arm of $97.3 \%$. Capdevila reported a success rate of $95.6 \%$ in the orthopedic cohort. This lack of difference in effectiveness may indicate that $40 \mathrm{mg}$ should be an adequate dose for spinal anesthesia in ambulatory orthopedic surgery.

Finally, there was a substantial difference in the administration of vasoactive agents (10\% in Capdevila's cohort compared to $22.7 \%$ in the chloroprocaine arm of our cohort). Whether this could be explained by a slightly higher peak 
sensory block (T9) with therefore more hemodynamic consequences in the chloroprocaine arm of our cohort compared to Capdevila's cohort (peak sensory block T10) remains questionable. This could be the result of different standard operating procedures regarding the use of vasopressor agents.

We strongly agree with the authors that chloroprocaine is a short-acting local anesthetic particularly suitable for short surgical procedures and to ambulatory management.

\section{ACKNOWLEDGEMENTS}

Funding. No funding or sponsorship was received for publication of this letter by any of the authors.

Authorship. All named authors meet the International Committee of Medical Journal Editors (ICMJE) criteria for authorship for this article, take responsibility for the integrity of the work as a whole, and have given their approval for this version to be published.

Disclosures. Elsbeth J Wesselink and Marcel A de Leeuw have nothing to disclose.

Compliance with Ethics Guidelines. This article is based on previously conducted studies and does not contain any studies with human participants or animals performed by any of the authors.

Data Availability. Data sharing is not applicable to this article as no datasets were generated or analyzed.
Open Access. This article is licensed under a Creative Commons Attribution-NonCommercial 4.0 International License, which permits any non-commercial use, sharing, adaptation, distribution and reproduction in any medium or format, as long as you give appropriate credit to the original author(s) and the source, provide a link to the Creative Commons licence, and indicate if changes were made. The images or other third party material in this article are included in the article's Creative Commons licence, unless indicated otherwise in a credit line to the material. If material is not included in the article's Creative Commons licence and your intended use is not permitted by statutory regulation or exceeds the permitted use, you will need to obtain permission directly from the copyright holder. To view a copy of this licence, visit http://creativecommons.org/licenses/by$\mathrm{nc} / 4.0 /$.

\section{REFERENCE}

1. Capdevila X, Aveline C, Delaunay L, et al. Impact of chloroprocaine on the eligibility for hospital discharge in patients requiring ambulatory surgery under spinal anesthesia: an observational multicenter prospective study. Adv Ther. 2020;37:541-51.

2. Wesselink E, Jansen-van den Hurk G, van der Vegt R, et al. Chloroprocaine versus prilocaine for spinal anesthesia in ambulatory knee arthroscopy: a doubleblind randomized trial. Reg Anesth Pain Med. 2019;44:944-9. 